\title{
Regulation of rDNA transcription in chloroplasts: promoter exclusion by constitutive repression
}

\author{
Rabah Iratni, Laurence Baeza, Alexandra Andreeva, Régis Mache, and Silva Lerbs-Mache ${ }^{1}$ \\ Laboratoire de Biologie Moléculaire Végétale, Université Joseph Fourier and Centre Nationale de la Recherche Scientifique, \\ BP 53X, F-38041 Grenoble Cédex, France
}

\begin{abstract}
Spinach chloroplasts contain two types of RNA polymerases. One is multimeric and Escherichia coli-like. The other one is not $E$. coli-like and might represent a monomeric enzyme of $110 \mathrm{kD}$. The quantitative relation of the two polymerases changes during plant development. This raises the question, how are plastid genes transcribed that contain $E$. coli-like and non- $E$. coli-like promoter elements during developmental phases when both enzymes are present? Transcription of the spinach plastid rrn operon promoter is initiated at three sites: P1, PC, and P2. P1 and P2 are preceded by $E$. coli-like promoter elements that are recognized by $E$. coli RNA polymerase in vitro. However, in vivo, transcription starts exclusively at PC. We analyzed different promoter constructions using in vitro transcription and gel mobility-shift studies to understand why P1 and P2 are not used in vivo. Our results suggest that the sequence-specific DNA-binding factor CDF2 functions as a repressor for transcription initiation of the $E$. coli-like enzyme at P1 and P2. We propose a mechanism of constitutive repression to keep the rrn operon in all developmental phases under the transcriptional control of the non-E. coli-like RNA polymerase.
\end{abstract}

[Key Words: Chloroplast; rDNA; repression; transcription]

Received May 25, 1994; revised version accepted October 5, 1994.

The existence of two different types of RNA polymerases in plastids, which was suggested some years ago (Greenberg et al. 1984; Lerbs et al. 1988; Little and Hallick 1988), seems to have been confirmed recently (Hess et al. 1993; Lerbs-Mache 1993). There is evidence that one of the two enzymes is Escherichia coli-like (Lerbs et al. $1985,1988 /$ and its subunits are encoded by the plastid rpo genes (Little and Hallick 1988; Hu and Bogorad 1990; Hu et al. 1991). The importance of $E$. coli-like promoter elements on the plastid genome for transcription initiation has been shown by mutational analysis (Bradley and Gatenby 1985; Gruissem and Zurawski 1985a,b). Although these studies have been made using relatively crude transcriptional extracts we can assume that it is the $E$. coli-like enzyme that recognizes E. coli-like promoter structures on the plastid genome.

The other RNA polymerase is nuclear encoded (Morden et al. 1991; Falk et al. 1993; Hess et al. 1993). As of yet, the promoter structures that are recognized by this enzyme on the plastid genome have not been defined, but in several cases, transcription initiation at sequences lacking the $E$. coli-like consensus has been shown (Gruissem et al. 1986; Sexton et al. 1990; Klein et al. 1992). Also, unusual promoters containing prokaryotic and nonprokaryotic sequence motifs have been described

${ }^{1}$ Corresponding author.
(Link 1984; Eisermann et al. 1990). Such non-E. coli-like sequences might be regarded as potential promoters for the nuclear-encoded enzyme. In spinach, two RNA polymerase activities can be separated by heparin-Sepharose chromatography, and the nuclear-encoded RNA polymerase might represent a monomeric enzyme of $110 \mathrm{kD}$ with some phage-like properties (Lerbs-Mache 1993).

The quantitative relation of the two RNA polymerases seems to change with plant development (Lerbs-Mache 1993), and a model was proposed in which the nuclearencoded enzyme transcribes preferentially plastid genes encoding the transcriptional/translational apparatus during early phases of plastid development to build up the transcriptional and translational machinery of the mature chloroplasts (Lerbs-Mache 1993; Baumgartner et al. 1993, Mullet 1993). During this phase the plastidencoded $E$. coli-like RNA polymerase is made up and transcribes preferentially the genes implicated in photosynthesis. This model raises the question how plastid housekeeping genes are transcribed during the later developmental phases when both RNA polymerases are present in plastids and might compete for transcription. This question becomes of special interest when $E$. colilike and non-E. coli-like promoter elements have been identified in promoter regions, as in the case of the spinach rrn operon (Lescure et al. 1985; Baeza et al. 1991).

The rrn operon upstream region of the spinach plastid 
genome contains two tandem $E$. coli-like promoter elements that are recognized in vitro by the $E$. coli RNA polymerase (Lescure et al. 1985). Transcription initiates at two different sites (P1 and P2). However, a detailed in vivo analysis of existing chloroplast ribosomal precursor RNAs from spinach revealed only $5^{\prime}$ ends located between the " $-35^{\prime \prime}$ and " -10 " elements of the second $E$. coli-like promoter. We named this position PC (Baeza et al. 1991). The localization of PC with respect to the two E. coli-like promoter elements makes it unlikely that the $E$. coli-like elements are implicated in a transcription initiation in vivo. This suggests that the PC-initiated transcripts are made by the $110-\mathrm{kD}$ phage-like RNA polymerase. Furthermore, it suggests that the $E$. coli-like enzyme has to be excluded from transcription initiation at $\mathrm{P} 1$ and $\mathrm{P} 2$ in leaf plastids in vivo.

Recently, we have characterized a sequence-specific DNA-binding factor (CDF2; Baeza et al. 1991) that should be implicated in the regulation of the rrn operon expression. Its DNA-binding site comprises the transcription start site $\mathrm{Pl}$, which suggests that it might function as a repressor for transcription initiation at P1. In this study we show that partially purified chloroplast $E$. coli-like RNA polymerase does not initiate transcription in vitro at the two $E$. coli-like $r r n$ operon promoters. Therefore, this enzyme reproduces in vitro what happens in vivo, and we used it to analyze the mechanisms by which transcription initiation at P1 and P2 is prevented. We also show that CDF2 acts as a repressor for rDNA transcription by the $E$. coli-like chloroplast enzyme and by the $E$. coli enzyme by blocking the access to the promoter region (P1) and by complexation and inactivation of the enzyme (P2). The implications of this mechanism of transcriptional regulation during plant and chloroplast development are discussed.

\section{Results}

The heparin-Sepharose-purified E. coli-like RNA polymerase does not transcribe the rrn operon

Transcriptional extracts were prepared from 500 grams of small spinach leaves from very young plants as described previously (Lerbs-Mache 1993). In contrast to our previous experiments (Baeza et al. 1991) we analyzed each heparin-Sepharose-eluted fraction individually by gel retardation using the rrn operon promoter (Fig. 1; mobility shift). As shown previously (Baeza et al. 1991), two complexes of different sizes (labeled L and S) were formed: Fractions 2-4 form the large complex $(\mathrm{L})$, and fractions 6-11 form the small complex (S), which we named CDF2 for chloroplast DNA-binding factor 2 . The analysis of each fraction permits us to separate the two different complexes and determine their DNA-binding sites individually (see below). Aliquots of $100 \mu \mathrm{l}$ of fractions $2-4$ and 6 and 7 were combined and used immediately for further assays or stored at $-70^{\circ} \mathrm{C}$ until usage. We have named these combined fractions CL (2-4) and CS $(6$ and 7$)$. Transcriptional activity elutes from the heparin-Sepharose column in two peaks, which are in-
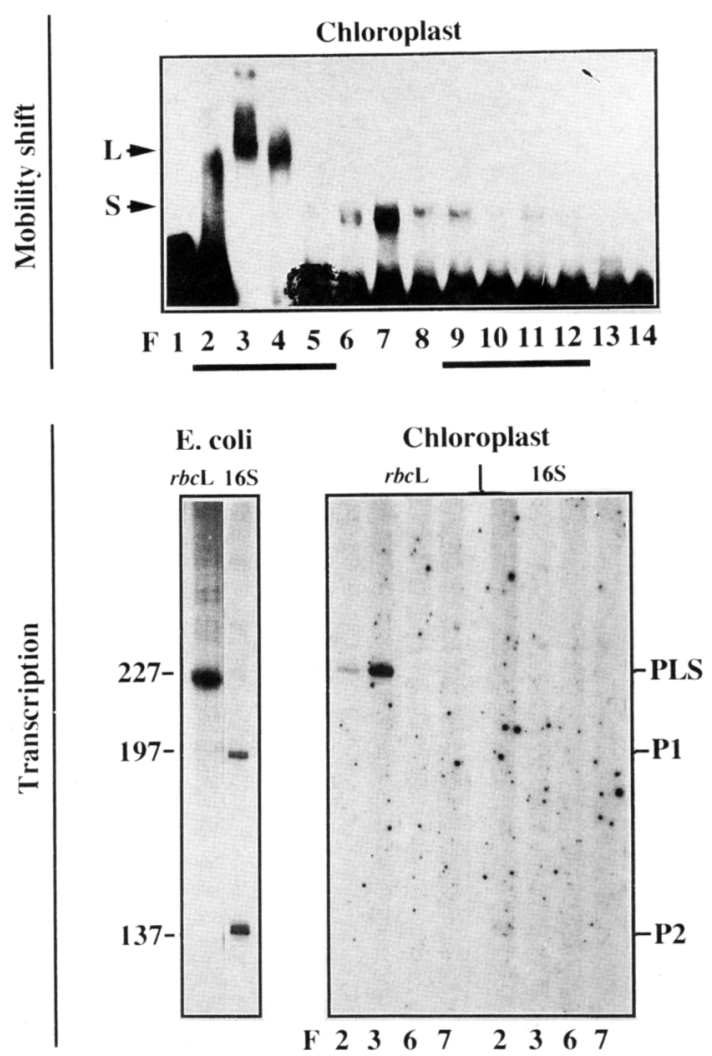

Figure 1. Characterization of chloroplast transcriptional extracts after heparin-Sepharose chromatography by gel mobilityshift and transcription assays. (Top) Each heparin-Sepharose fraction was analyzed by gel retardation (F 1-14) using the 163bp $16 S$ rDNA promoter-containing fragment. The small and the large complex are indicated $(S, L)$. Transcriptionally active fractions are underlined. (Bottom) In vitro transcription of the $r b c \mathrm{~L}$ or 16S rRNA gene promoter region was performed using 0.5 unit of $E$. coli RNA polymerase (Boehringer Mannheim) or $8 \mu 1$ of heparin-Sepharose fractions 2, 3, 6, or 7 (cf. with gel mobilityshift assay). The sizes of the transcripts (left) correspond to transcription initiation at the $r b c L$ (PLS) or the two $E$. coli-like rrn operon promoters $\mathrm{P} 1$ and $\mathrm{P} 2$ (indicated at right).

dicated by horizontal bars. The first peak (fractions 2-5) comprises the proteins of the large complex. When analyzed by antibody-linked polymerase assays, it was found that this peak contains the $E$. coli-like RNA polymerase polypeptides (Lerbs et al. 1985; Lerbs-Mache 1993), whereas the second peak (fractions 9-12) contains only the $110-\mathrm{kD}$ non-E. coli-like RNA polymerase polypeptide (Lerbs-Mache 1993). We have analyzed only the first peak of transcriptional activity (i.e., the E. coli-like chloroplast RNA polymerase).

In vitro transcription studies were performed immediately after extract preparation with fractions $2,3,6$, and 7 using two different DNA templates /Fig. 1; transcription). One plasmid (pTZ19-PLS-Ta; Chen and Orozco 1988) contains a plastid DNA fragment that harbors the E. coli-like promoter of the spinach $r b c L$ gene (Orozco et al. 1985). It serves as control for transcription by the $E$. 
coli-like enzyme because it represents the promoter of a photosynthetic gene. The other plasmid (pTZ19-16S-Ta) contains the 163-bp DNA fragment harboring the spinach $r r n$ operon promoter. Both plastid DNA fragments are inserted upstream of the strong, rho-independent $E$. coli thr attenuator, which terminates transcription efficiently either by the $E$. coli or the chloroplast RNA polymerases (Chen and Orozco 1988; Lerbs-Mache 1993). Transcription from the $r b c \mathrm{~L}$ promoter should produce a 227-nucleotide RNA; transcription from the P1 and P2 promoters (16S) should produce 197- and 137-nucleotide RNAs, respectively. RNAs corresponding to these sizes are found in control experiments performed with $E$. coli RNA polymerase. The chloroplast extract (heparinSepharose fractions 2 and 3 ) starts transcription efficiently at the $E$. coli-like $r b c \mathrm{~L}$ gene promoter but not at the two $E$. coli-like promoters of the $r r n$ operon. Heparin-Sepharose fractions 6 and 7 are not active transcriptionally (right).

This result shows that the chloroplast enzyme of the first peak probably reproduces in vitro what happens in vivo. Now we have to ask how the enzyme of this extract can discriminate between the $E$. coli-like promoter of the $r b c \mathrm{~L}$ gene and the two $E$. coli-like promoters of the $r r n$ operon. For this reason we analyzed in more detail the protein-DNA interactions (the formation of the two complexes $\mathrm{L}$ and $\mathrm{S}$ ) of the chloroplast extracts with the rrn operon promoter region by DNase I footprinting and gel retardation.

The large complex represents an association of the $\mathrm{E}$. coli-like chloroplast RNA polymerase with the DNA-binding factor CDF2

From the transcription studies presented in Figure 1 we can conclude that the small complex is not a subunit of RNA polymerase. It is also not a $\sigma$-like factor of RNA polymerase, as plastid $\sigma$-like factors do not bind directly to DNA (Tiller et al. 1991); therefore, it should represent a potential transcription regulator with specific DNAbinding properties. DNase I footprinting experiments (Fig. 2) show that the protected region of the large complex includes the -35 and -10 elements of the second E. coli-like promoter and the initiation site P2. It is quite similar in size and position to the region that is protected by the $E$. coli RNA polymerase and by chloroplast transcriptional extracts on the $p s b \mathrm{~A}$ promoter sequence $(\mathrm{Za}$ itlin et al. 1989; Eisermann et al. 1990). The small complex protects the transcription start site $\mathrm{P} 1$ and the -35 element of the E. coli-like promoter P2. This protected region extends the CDF2 binding site as it was determined previously by exonuclease III digestion (Baeza et al. 1991). This might be attributable to the different methods that were used or to the fact that the large and the small complex are separated from each other. The fixation of CDF2 to the DNA should block the access of the $E$. coli-like RNA polymerase to the promoter region of P1 (see schematic representation of the two complexes, below, in Fig. 6, top). Furthermore, both complexes overlap over a region of $9 \mathrm{bp}$. This suggests that

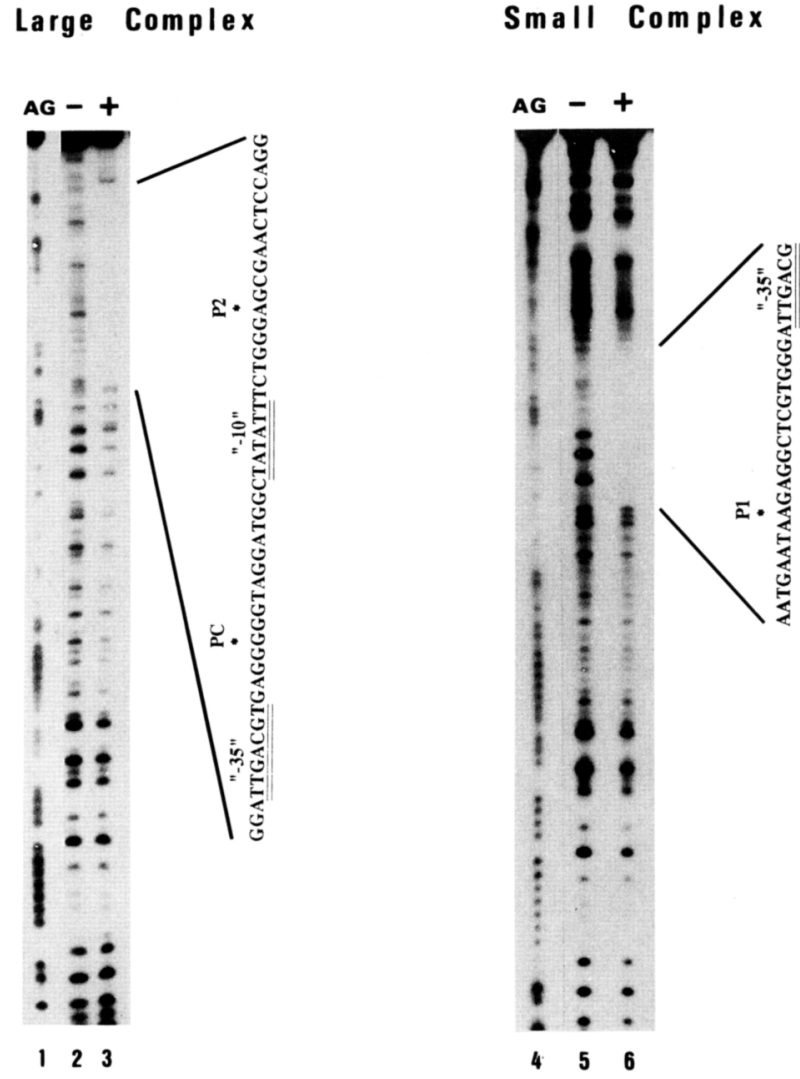

Figure 2. Localization of the large and the small complex on the DNA by DNase I footprinting. DNA was incubated with $(+)$ extract CL (left) or CS (right) or with BSA (-) before DNase I treatment. The DNA sequence was established by chemical cleavage of A and G (AG). (CL) Combined heparin-Sepharose fractions $2-4 ;(C S)$ combined fractions 6 and 7 (see Fig. 1).

they should exclude each other from binding to DNA or that they should interact with each other in the overlapping region.

When we characterized the strength of the proteinDNA affinity of the two complexes by raising the salt concentration and introducing heparin during the binding reaction we obtained a surprising result (Fig. 3). At $200 \mathrm{~mm} \mathrm{NaCl}$ the large complex disappears and a smaller complex forms that migrates on the same gel at the same position as the small complex (Fig. 3, top, cf. lanes 2 and 6). Both complexes are stable up to $600 \mathrm{mM} \mathrm{NaCl}$, (lanes 3 and 7), start to diminish at $700 \mathrm{~mm} \mathrm{NaCl}$, and disappear completely at $1 \mathrm{M} \mathrm{NaCl}$ (lanes 4,8 and 5,9 ). The same holds true when we introduce heparin during the binding reaction (Fig. 3, bottom). The large complex transforms into the small complex at $10 \mu \mathrm{m}$ heparin (lane 4). Both small complexes are stable at $20 \mu \mathrm{M}$ and dissociate at 100 $\mu \mathrm{M}$ of heparin (lanes 5,11 and 2,8).

This transformation of the large into the small complex also occurs during storage of the extracts at $-20^{\circ} \mathrm{C}$. Fraction CL was reanalyzed by gel retardation 3 days, 14 days, and 1 year after freezing in the presence of $1.5(-)$ and $5\left(+\mid \mathrm{mM} \mathrm{Mg}^{2+}\right.$ (Fig. 4A). The dissociation of pro- 

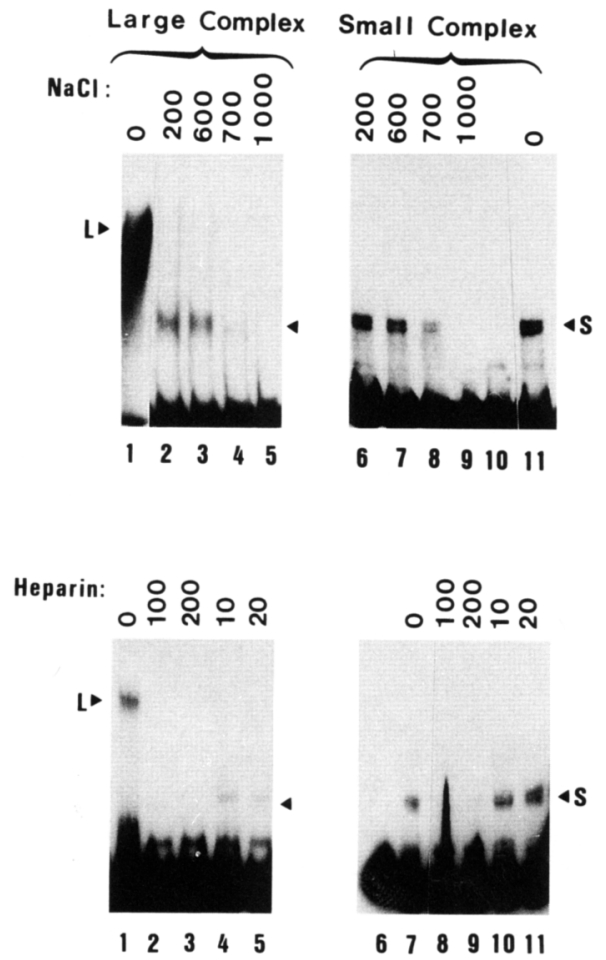

Figure 3. Characterization of the DNA affinity of the large (L) and the small (S) complex. Gel mobility-shift assays were performed using the labeled 163-bp 16S rDNA promoter-containing fragment. Increasing concentrations of $\mathrm{NaCl}(200 \mathrm{mM}-1 \mathrm{M}$; top) and increasing concentrations of heparin $(10-200 \mu \mathrm{M}$; bottom) were introduced during incubation of the DNA fragment with fraction CL and CS (see Fig. 2 legend) for complex formation. Lanes 10 (top) and 6 (bottom) represent the DNA fragment without addition of protein extract.

teins already starts after 3 days (lanes 1,2). After 14 days, only the small complex forms at $1.5 \mathrm{mM} \mathrm{Mg}^{2+}$. But the large complex can still be restored by increasing the $\mathrm{Mg}^{2+}$ concentration to $5 \mathrm{~mm}$ (lanes 3,4$)$. In addition, an intermediate complex appears with the 14-day extract [lane 4, L( $(\Delta)]$. This result explains that in Figure 1, lanes 2 to 4 , only the large complex is formed, although the small complex forming proteins should be present. This result tells us also that after preparation of a plastid extract we have no more than 3 days to characterize the large complex and that under this condition, it is not technically feasible to purify this complex to homogeneity. After 1 year, the extract has lost transcriptional activity completely and only the small complex forms (lanes 5,6). The DNA-binding site of this complex, as determined by DNase I footprinting, corresponds exactly to the DNA-binding site of the small complex that is formed by the CS fraction (Fig. 4B, cf. with Fig. 2, right).

The presence of CDF2 in the CL fraction was further confirmed by UV cross-linking of CS and CL fraction polypeptides to oligonucleotide hybrids corresponding to the CDF2-binding site. In both cases, two small polypeptides that migrate corresponding to 35 and $33 \mathrm{kD}$ were linked specifically to the oligonucleotide hybrids that correspond to the CDF2-binding site (Fig. 4C).

Thus far, our results show that the CL fraction contains RNA polymerase as well as CDF2. Now, we must determine whether both components compete for binding to the rrn promoter or whether they can bind concomitantly and interact in the overlapping region (cf. Fig. 6 , top). In the case of competition we should obtain only two different types of complexes in gel retardation assays, corresponding to binding of CDF2 or RNA polymerase. Concomittant binding of both components should result in the formation of a third type of complex. The existence of three types of complexes (Fig. 4A, lane 4) indicates that $L$ should correspond to binding of RNA polymerase plus CDF2, $\mathrm{L}\langle\Delta\rangle$ to binding of RNA polymerase, and $\mathrm{S}$ to binding of CDF2. If this assumtion is correct, we should obtain only the L $(\Delta)$ complex, if we prevent the fixation of CDF2. Therefore, we deleted the CDF2-binding site from the DNA template by cleavage with Mnll. The two cleavage sites of Mnll are indicated by vertical arrows in Figure 6 (top). The resulting DNA construction is named $\Delta 16 \mathrm{~S}$. As expected, incubation of 14-day CL extract with this deletion shows only the formation of the $L(\Delta)$ complex (Fig. 5, left, cf. lanes 2 and 4 ). This experiment demonstrates that CDF2 is a component of the $L$ complex. But we must also show that the $\mathrm{L}$ complex contains RNA polymerase in addition to CDF2. This was done by immunological cross-reaction with antibodies raised against the E. coli RNA polymerase (Fig. 5 , right). Complexation with the antibodies causes a supershift (lane 2), thus demonstrating the presence of the E. coli-like chloroplast RNA polymerase in the $\mathrm{L}$ complex.

These results show that CDF2 complexes with the $E$. coli-like plastid RNA polymerase on the rrn promoter region to form the large complex. But, as the large complex is located on a DNA sequence other than the small complex (see Figs. 2 and 4), it implies that CDF2 loses its specific DNA-binding capacity when it contacts the RNA polymerase. From the transcription experiment shown in Figure 1 we know that in this form (as complex with CDF2) the RNA polymerase does not initiate transcription at $\mathrm{P} 2$. This suggests that it is the association of the enzyme with CDF2 that blocks transcription initiation at $\mathrm{P} 2$.

\section{Complexation of CDF2 with the E. coli-like plastid RNA polymerase is necessary to prevent transcription initiation at $P 2$}

If this assumption is correct we should obtain initiation at P2 if CDF2 cannot fix to the template. Therefore, we tested the $\Delta 16 \mathrm{~S}$ construction (Fig. 5, left, lanes 3,4, and Fig. 6, top) in mobility-shift and transcription assays using freshly prepared CL extract (Fig. 6). The deletion of the CDF2-binding site abolishes the fixation of CDF2 (Fig. 6, Mobility shift, lanes 1-4) and consequently, should result in the fixation of the E. coli-like RNA polymerase depleted of CDF2 [complex L $(\Delta)$ ]. Correspondingly, incubation of the deleted DNA fragment with hep- 
Figure 4. Degradation of the large complex during storage of extracts and comparison of the $C L$ and $C S$ fractions by UV cross-linking of proteins to the CDF2-binding site. (A) Aliquots of fraction CL were thawed after 3 days (lanes 1,2), 14 days (lanes 3,4), and 1 year (lanes 5,6 ) of storage at $-70^{\circ} \mathrm{C}$. The extracts were incubated with the 16S rDNA promoter fragment in the presence of $1.5 \mathrm{~mm} /-\mid$ or $5 \mathrm{~mm}$ $\mathrm{Mg}^{2+}$, and complex formation was analyzed by gel shift assays. (B) The small complex that dissociates from the large and is stable for 1 year (lanes 5,6) was localized on the DNA sequence by DNase I footprinting. DNA was incubated with protein extract $(+)$ (stored for $1 \mathrm{yr}$ ) or with BSA $(-)$ before DNase I treatment. AG corresponds to the A and G cleavage of the DNA fragment. $(C)$ Labeled oligonucleotide

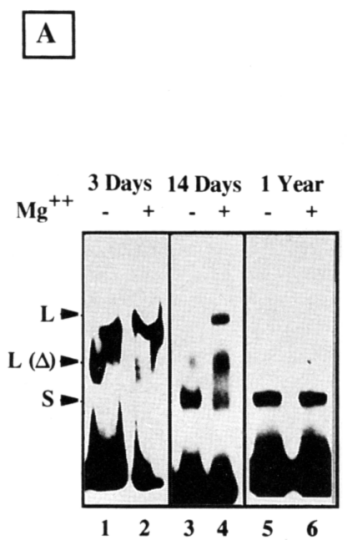
hybrids ( $5 \mathrm{ng}, 50,000 \mathrm{cpm}$ ) corresponding to the CDF2-binding site (oligonucleoide $1 / 2$ ) were incubated with chloroplast extract CL (lanes 1,2$)$ (stored for 1 month) or CS (lanes 3,4$)$ in the presence of 50 ng unlabeled oligonucleotide hybrids $1 / 2$ as competitor (lanes $1,3)$ or $50 \mathrm{ng}$ unlabeled hybrids $3 / 4$ that do not include the CDF2-binding site (lanes 2,4). After cross-linking by UV treatment DNA-protein complexes were analyzed on 10\% SDS-polyacrylamide gels. For an explanation of CL and CS, see the legend to Fig. 2.

arin-Sepharose fraction 3 (see Fig. 1) results in the formation of a slightly smaller complex than incubation of the nondeleted DNA fragment (lanes 5,6). In vitro transcription of the two constructions with heparin-Sepharose fraction 3 shows that the deletion of the CDF2binding site enables the RNA polymerase to initiate transcription at P2 (Fig. 6, transcription). This result confirms our assumption that CDF2 acts as a repressor for transcription of the $r r n$ operon by the E. coli-like RNA polymerase.

To analyze in more detail the interactions of CDF2 with the E. coli-like chloroplast RNA polymerase, we constructed three mutations of the rrn operon promoter

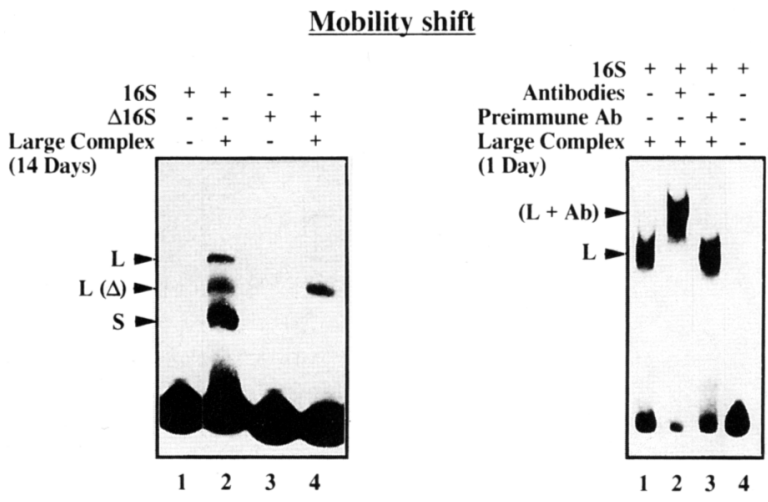

Figure 5. The large complex represents an association of CDF2 with the E. coli-like chloroplast RNA polymerase. (Left) Fourteen-day CL extract was incubated with the entire $16 \mathrm{~S}$ rDNA promoter fragment (lane 2) or with the $\Delta 16 \mathrm{~S}$ fragment (lane 4) where the CDF2-binding site is deleted by cleavage with MnlI (see Fig. 6, top), in the presence of $5 \mathrm{~mm} \mathrm{Mg}^{2+}$. (Lanes 1,3) The labeled DNA fragments. (Right) The entire 16S rDNA promoter fragment was incubated with freshly prepared CL extract (lanes $1-3$ ) in the presence of antibodies raised against $E$. coli RNA polymerase (lane 2) or preimmune serum (lane 3). (Lane 4) The labeled DNA fragment. and separated the enzyme from the factor to perform reconstitution assays. The mutations are shown in Figure 7 (top). We changed the -10 and -35 promoter elements of P2 (M3 and M2) and two nucleotides in the most conserved part of the CDF2-binding site $(\mathrm{Ml}$; for sequence comparison, see Baeza et al. 1991). Mobilityshift assays show that M1 completely abolishes the fixation of CDF2 to the DNA (lanes 8-11). On the other hand, changes in the overlapping region of the two complexes (M2) do not interfere with the binding of the factor (lanes 12-15). Neither do changes in the -10 element (M3; lanes 16-19).

Transcription of the three constructs by the E. coli RNA polymerase gives the expected transcripts (Fig. 7, transcription). M2 and M3 largely diminish or completely abolish transcription initiation at P2; M1 abolishes initiation at P1 (lanes 1-4). The chloroplast extract does not initiate transcription on the promoter region of the wild type; however, when CDF2 cannot bind any more to the template (M1) the enzyme can initiate at P2 (lanes 5,6).

To test the two other mutations with the chloroplast enzyme and for reconstitution assays we had to separate CDF2 from the enzyme. This was achieved by stepwise ammonium sulfate precipitation (Fig. 8). The presence of CDF2 was checked in the different fractions by gel retardation assays using an oligonucleotide-tetramer of the CDF2-binding site (mobility shift). The enzyme activity was measured by transcription of the $r b c \mathrm{~L}$ gene promoter (transcription, top). With 50\% ammonium sulfate we precipitated only the enzyme without detectable traces of CDF2 (lanes 2,5). Between $50 \%$ and $60 \%$ the enzyme precipitates along with the factor (lanes 3,6 ), and at concentrations $>60 \%$ we can obtain a fraction that only contains the factor (lanes 4,7 ). The CDF2-depleted enzyme transcribes now the wild type with the same efficiency as M1, but it does not initiate on the two constructions, M2 and M3, in which the two E. coli-like promoter elements have been changed (lanes $8,10-12$ ). If 

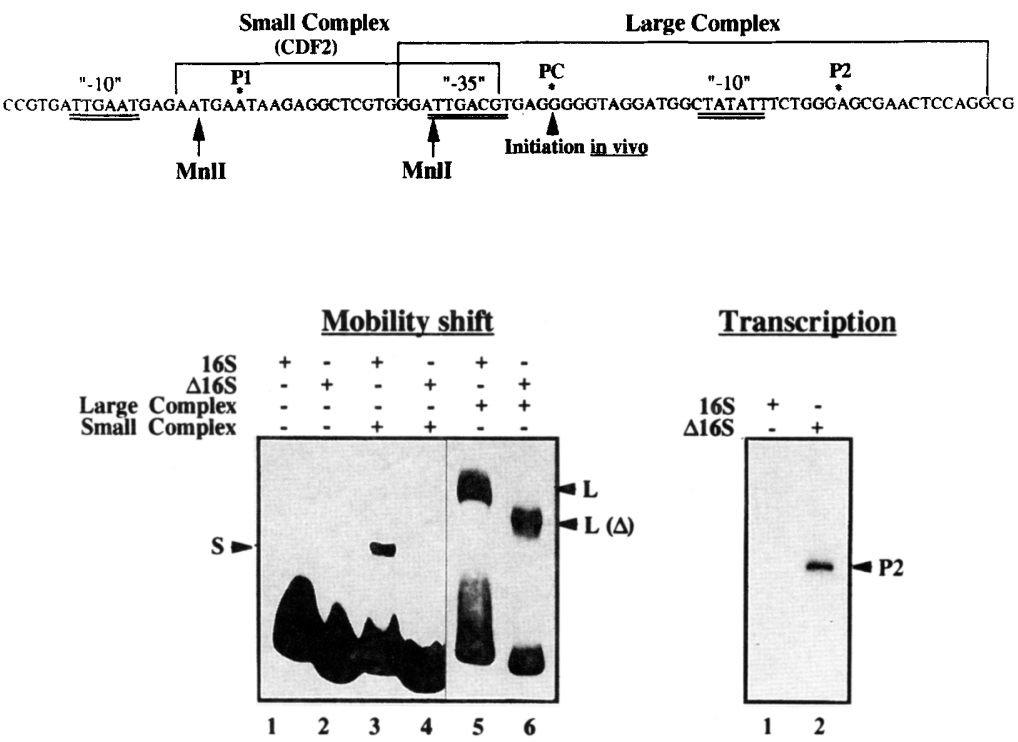

\section{Transcription}

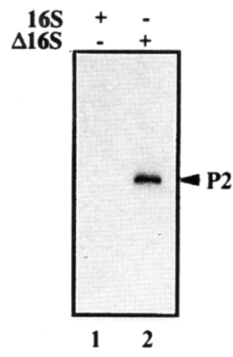

Figure 6. CDF2 represses transcription initiation at the P2 promoter by complexation with the RNA polymerase. The binding of the small (S) and the large (L) complexes to the DNA is represented schematically at the top. Mobility-shift assays were performed with fraction CL (lanes 5,6) and CS (lanes $3,4)$ and the rrn operon promoter fragment before $(16 \mathrm{~S}$, lanes 3,5$)$ or after $(\Delta 16 \mathrm{~S}$, lanes 4,6$)$ deletion of the CDF2-binding site by cleavage with MnlI. Lanes 1 and 2 represent the two labeled DNA fragments without protein extract. In vitro transcription assays were done using plasmids pTZ19-16S-Ta (lane 1) and pTZ19- $\Delta$ 16S-Ta (lane 2) and fraction CL. For CL and CS, see Fig. 2 legend. we reintroduce CDF2, initiation at $\mathrm{P} 2$ is abolished completely on the wild type (lanes 13,14$)$, but there is still initiation on M1 (lanes 17,18$)$. The fact that the addition of CDF2 reduces the transcription (cf. lanes 17 and 18), is probably attributable to the presence of an additional unspecified transcription inhibitor in the CDF2-containing fraction (S. Lerbs-Mache and R. Iratni, unpubl.).

\section{CDF2 also interacts with the E. coli RNA polymerase}

Chloroplast $\sigma$-like factors are known to interact with the RNA polymerase core enzyme of $E$. coli and to stimulate correct initiation on plastid promoters (Bülow and Link 1988; Lerbs et al. 1988; Tiller et al. 1991). This implies a similarity in one of the chloroplast RNA polymerases (which we call $E$. coli-like) with the $E$. coli enzyme. As CDF2 is not a $\sigma$-like factor but interferes with the rec- ognition of $E$. coli-like promoter elements on the plastid genome, we wanted to know whether it could also interact with the $E$. coli RNA polymerase. Therefore, we performed transcription assays using the $E$. coli enzyme supplemented with different concentrations of CDF2 (Fig. 8, transcription). The addition of CDF2 has no effect on the transcription of the $r b c L$ promoter because it does not contain the CDF2-binding site and, consequently, the factor cannot associate with the enzyme (lanes 2-4). However, transcription initiation at the rrn promoter is prevented by CDF2 as in the homologous system (lanes 5-7). This inhibition should be caused by CDF2 and not by other transcriptional inhibitors that could be present in the CDF2-containing fraction, as it can be overcome if the factor is "inactivated" before addition of the enzyme by binding to oligonucleotides, which correspond to the CDF2-binding site (lanes 8-11).

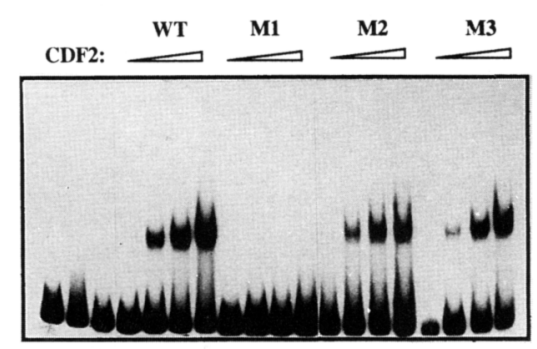

122345567789910111213141516171819

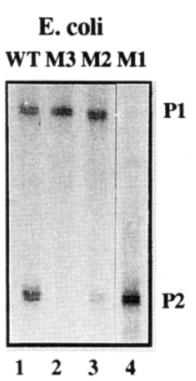

Figure 7. Mutational analysis of the rrn operon promoter. The three mutations, $\mathrm{M} 1, \mathrm{M} 2$, and $\mathrm{M} 3$ (top) were introduced into the $r r n$ promoter region of the plasmid pTZ19-16S-Ta (WT). They were tested with the isolated promoter fragments by mobility-shift assays without extract (lanes 1-3) and using $4,8,12$, and $16 \mu l$ of chloroplast extract CS (lanes 4-7, 8-11, 12-15, and 1619 , respectively) and by in vitro transcription of the plasmids with 0.5 unit of $E$. coli RNA polymerase (lanes 1-4) and with the chloroplast CL fraction (lanes 5,6 ). For CL and CS, see Fig. 2 legend. 


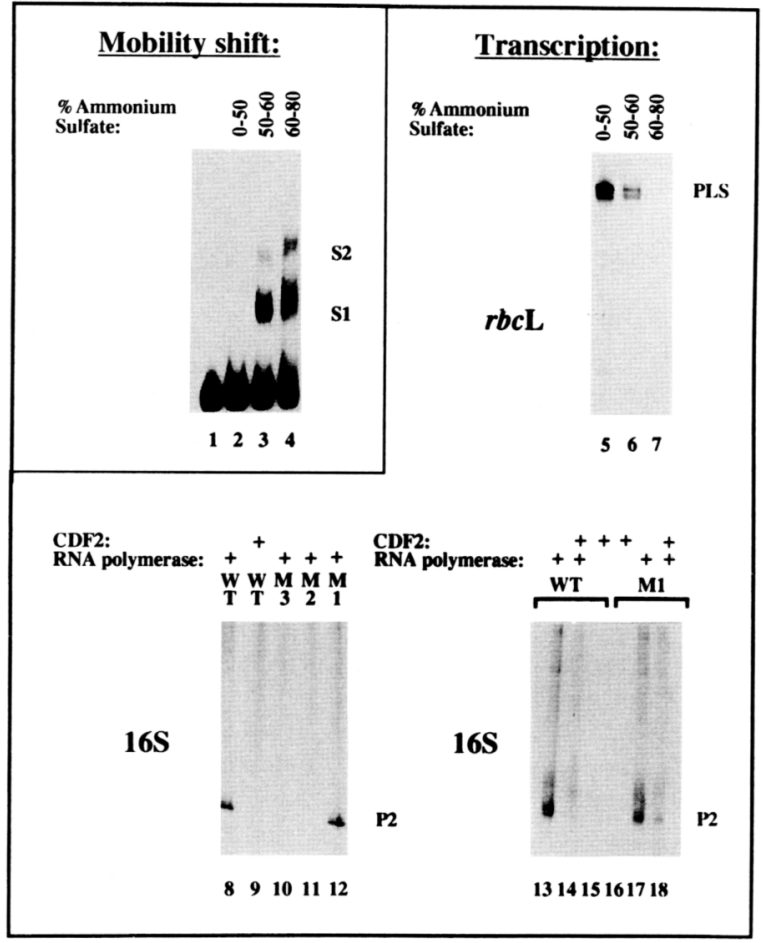

Figure 8. Separation of the E. coli-like chloroplast RNA polymerase from CDF2 and reconstitution assays. Ammonium sulfate fractions were tested by mobility-shift assays using an oligonucleotide-tetramer of the CDF2-binding site (lanes 1-4) and by in vitro transcription of pTZ19-LS-Ta $(\mathrm{rbcL}$ gene promoter, lanes 5-7). The RNA polymerase fraction $150 \%$ ammonium sulfate) was used for in vitro transcription of pTZ19-16S-Ta (WT) and all three $r m$ operon mutations (lanes $8,10-12$ ). The function of the CDF2 fraction $(2 \mu \mathrm{l}$ of the $60-80 \%$ ammonium sulfate fraction) was tested by reconstitution with the enzyme on the wild-type plasmid (lanes 13-15) and on the Ml plasmid (lanes 16-18). For mutations, see Fig. 6. (S1) CDF2 monomer; (S2) CDF2 dimer.

If we analyze the interaction of CDF2 with the $E$. coli enzyme on the rrn operon promoter by mobility-shift assays, we observe that the presence of CDF2 leads to the formation of a larger complex on the entire rrn promoter (mobility shift, lanes 6,7) but not on M1 where CDF2 cannot bind (lanes 4,5). This complex corresponds to the $\mathrm{L}$ complex of the homologous system. If the concentration of CDF2 reaches the concentration used in the transcription assay (Fig. 9, lanes 1-7), the complex that is formed by the $E$. coli enzyme disappears completely and the $\mathrm{L}$ complex analog is highly reduced (not shown). This result is consistent with the idea that CDF2 complexes with the $E$. coli enzyme and this association leads to the detachment of the complex from the DNA.

\section{Discussion}

Higher plant plastid rRNA operons show the typically prokaryotic gene order of $16 \mathrm{~S}, 23 \mathrm{~S}$, and 5S rDNA. They are transcribed as large precursor RNAs that are processed subsequently into the various mature rRNA species (Strittmatter and Kössel 1984; Dormann-Przybyl et al. 1986). Very little is known of the processes engaged in transcription and processing. Transcription has been studied by expression of the genes in heterologous systems such as $E$. coli (Tohdoh et al. 1981; Lescure et al. 1985; Delp et al. 1987) and by in vitro transcription using run-on assays or highly purified chloroplast enzymes (Briat et al. 1987; Sun et al. 1989; Rajasekhar et al. 1991). For maize and pea, it was reported that transcription starts downstream of a -10 and $-35 E$. coli-like promoter sequence (Strittmatter et al. 1985; Sun et al. 1989). This sequence corresponds to the P2 promoter of the spinach $r m$ operon. We have noticed, however, that maize capping experiments were performed by hybridization of capped RNA to plastid DNA restriction fragments (i.e., the exact position of the capped nucleotide in the sequence is not determined). In pea, the capping experiment has been made after in vitro transcription with purified chloroplast RNA polymerase (i.e., the in vivo transcription start site has not been determined). To our knowledge, a clear determination of the $5^{\prime}$ capped nucle-
Figure 9. Interactions of $\mathrm{CDF} 2$ with $E$. coli RNA polymerase. In vitro transcription of pTZ19-LS-Ta (lanes 2-4) and pTZ19-16S-Ta (lanes 5-7, 8-11) was performed using 0.5 unit of $E$. coli RNA polymerase (lanes 2,5, 8-11) and $2 \mu$ (lanes $3,6,10,11$ ) or $4 \mu \mathrm{l}$ of fraction CS (lanes 4,7$)$. In the competition experiments (lanes 8-11) transcription assays were incubated for 5 min with (lanes 9,10$)$ or without (lanes 8,11) $50 \mathrm{ng}$ of oligonucleotide-tetramer of the CDF2-binding site before addition of the $E$. coli enzyme. In mobilityshift assays the rrn promoter (lane 8) was incubated with $0.4 \mu \mathrm{l}($ lanes $1,4,6)$ or $0.8 \mu \mathrm{l}$ (lanes 2,5,7) of fraction CS and 1 unit of $E$. coli RNA polymerase (lanes 3-7) before electrophoresis. For CS, see Fig. 2 legend.
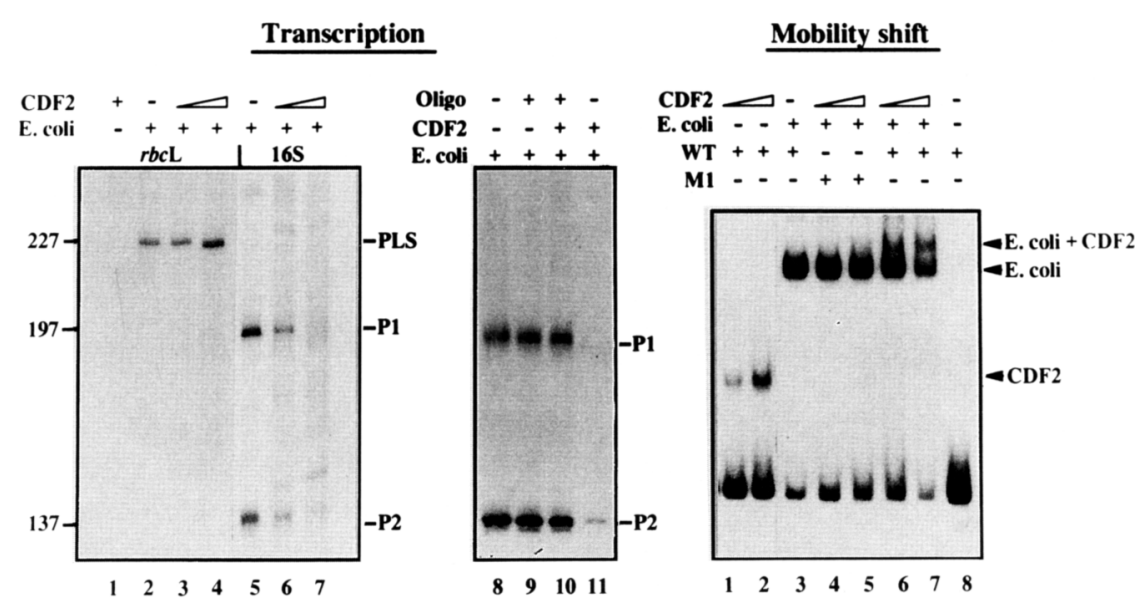
otide of plastid precursor rRNA has only been made for Euglena gracilis (McGarvey et al. 1988). Here, the first nucleotide is a $G$, which is followed by four $C$ residues, and the initiation site is not preceded by an $E$. coli-like promoter sequence. Furthermore, there is strong evidence that the Euglena rrn operon is transcribed by an RNA polymerase other than the one encoded by the plastid E. coli-like rpo genes (Narita et al. 1985; Little and Hallick 1988). This situation resembles more closely what we find in spinach plastids than what was reported for pea and maize. Therefore, at present, there are not enough data available on the rrn expression in other plant species to allow a generalization of this proposed model of transcriptional regulation.

In spinach, of the three transcription start sites $\langle\mathrm{P} 1$, PC, and P2; see Fig. 51, only P1 and P2 are preceded by $E$. coli-like promoter sequences and are recognized by the $E$. coli RNA polymerase and by highly purified chloroplast $E$. coli-like RNA polymerase in in vitro transcription assays (Lescure et al. 1985; Briat et al. 1987). However, in vivo transcription initiation starts exclusively at PC in plastids of all leaf types analyzed so far (Baeza et al. 1991; S. Lerbs-Mache, unpubl.). This is very surprising, and we had to ask why P1 and P2 are not used in vivo. Spinach plastids contain at least two different RNA polymerases: one is multimeric and $E$. coli-like, and the other is active as a single subunit enzyme (Lerbs et al. 1985, 1988; Lerbs-Mache 1993). Both enzymes coexist in leaf plastids of very young spinach plants (Lerbs-Mache 1993) where transcripts are initiated at PC (Baeza et al. 1991). Therefore, the E. coli-like enzyme has to be excluded from recognition of the $\mathrm{P} 1$ and $\mathrm{P} 2$ promoters in vivo. To elucidate the mechanisms of such transcriptional regulation we have started to characterize promoter-protein complexes formed between chloroplast extracts that contain the E. coli-like plastid RNA polymerase and the rrn operon promoter. We have demonstrated that two DNA-protein complexes of different sizes were formed. The smaller one, which was named CDF2, was further characterized by determination of its DNA-binding site and the DNA-binding proteins (Baeza et al. 1991). The DNA-binding site of CDF2 comprises the transcription start site $\mathrm{P} 1$. Thus, fixation of CDF2 on the DNA should prevent any initiation at the P1 promoter. However, we were never able to reproduce the results published by Briat et al. (1987). In our hands, purified chloroplast RNA polymerase, even if isolated in exactly the same way as reported by these investigators, always initiates exclusively at P2 or not at all (if $\sigma$-factors are lost).

In this paper we show that the large complex represents an association of CDF2 with the E. coli-like plastid RNA polymerase. It was very difficult to get a DNase I footprint of this complex because this complex is very unstable and DNA-protein interactions are very weak (Figs. 3 and 4). During storage, the two components of the complex lose their capacity to interact with each other, and the affinity of the E. coli-like RNA polymerase for promoter-binding ceases. Both functions can be restored partially by increasing the $\mathrm{Mg}^{2+}$ concentration
(Fig. 4). The affinity of the RNA polymerase to DNA is much lower than that of CDF2 (Fig. 3). At $200 \mathrm{~mm} \mathrm{NaCl}$, promoter binding of the enzyme is no longer detectable (Fig. 3, top, lane 2). This correlates with the data obtained for promoter binding of the $E$. coli enzyme, where complex formation diminishes for $>90 \%$ between 50 and $200 \mathrm{~mm}$ of $\mathrm{NaCl}$ (Hinkle and Chamberlin 1972).

The DNA-binding site of the large complex comprises the two E. coli-like promoter elements of P2 (Figs. 2 and 5). It is quite similar in size and position (relative to the transcription initiation start site) to the $p s b \mathrm{~A}$ promoter sequence that has been shown to be protected by $E$. coli RNA polymerase and by chloroplast transcriptional extracts in exonuclease mapping (Eisermann et al. 1990). In the following, we discuss two models to exclude transcription from the $\mathrm{P} 2$ promoter. The large and the small complex overlap in a region of 9 bp (Fig. 6, top). This overlap might be sufficient to exclude the concomitant fixation of the two complexes for steric reasons. But this would not explain our finding that CDF2 is a constituent of the large complex. It is more likely to assume that CDF2 interacts with the RNA polymerase in this region. This interaction could cause conformational changes in both complexes that lead not only to the detachment of CDF2 from its binding sequence but subsequently to the detachment of the CDF2-complexed RNA polymerase from the promoter P2 (Fig. 10). This model would also explain the instability of the complex, as it is a complex that is ready to detach from the template. Our results suggest further that the interaction of CDF2 with the enzyme is dependent on the fixation of the two protein complexes to the DNA and does not occur in solution; otherwise CDF2 should also inhibit transcription of the $r b c \mathrm{~L}$ gene (Figs. 1 and 8 ). If the protein-protein interactions between CDF2 and the E. coli-like RNA polymerase on the DNA template are prevented (either by deletion or mutation of the CDF2-binding site or by separation of CDF2 from the enzyme), P2 becomes accessible to initiation (Figs. 5-7).

Our findings strongly suggest a role of CDF2 as repressor for transcription initiation by the $E$. coli-like chloroplast RNA polymerase at $\mathrm{P} 1$ and $\mathrm{P} 2$. The physiological significance of this type of repression is not yet clear. However, it was shown recently that in $E$. coli the formation of active ribosomal subunits requires coupling of rRNA transcription and ribosome assembly (Lewicki et al. 1993). This coupling demands definite transcription rates for the rrn operon expression, and if the operon is placed under the control of a T7 instead of an E. coli promoter, this assembly is disturbed. Preliminary results indicate that the spinach rrn operon is transcribed by the $110-\mathrm{kD}$ "T7-like" chloroplast enzyme, and that in this case, CDF2 acts as initiation factor or activator of transcription. The $110-\mathrm{kD}$ enzyme is present in chloroplasts of all plant developmental stages analyzed thus far. The E. coli-like RNA polymerase is not always detected (S. Lerbs-Mache, unpubl.). Therefore, we suggest that this type of repression serves to keep the $r m$ operon under transcriptional control of the same type of RNA polymerase during all stages of plant development. 


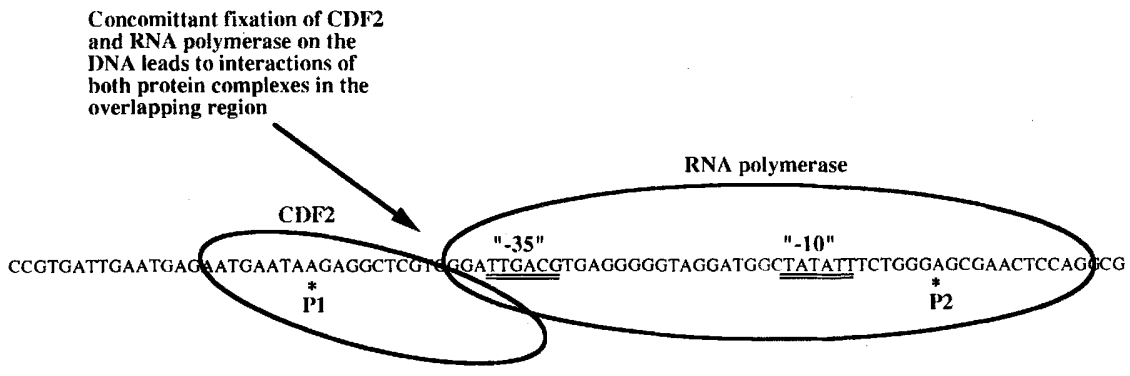

Figure 10. Schematic representation of CDF2 and RNA polymerase interactions.

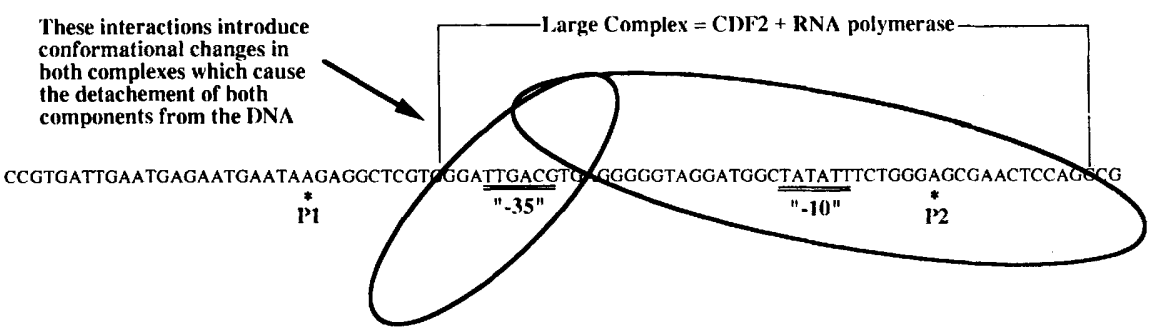

Mobility-shift assays

Gel retardation assays were performed according to Straney and Crothers (1985). One nanogram of labeled DNA was incubated in a mixture $(20 \mu \mathrm{l})$ containing $44 \mathrm{~mm}$ Tris $(\mathrm{pH} 8.0), 10 \mathrm{~mm}$ $\mathrm{NaCl}, 0.4 \mathrm{~mm}$ EDTA, $0.8 \mathrm{~mm}$ DTT, $1 \mu \mathrm{g}$ of poly[d(I-C)], and 1.5 $\mathrm{mM} \mathrm{MgCl} 2$ if not otherwise indicated with $4 \mu \mathrm{l}$ of chloroplast extract at $30^{\circ} \mathrm{C}$ for $15 \mathrm{~min}$. DNA-protein complexes were analyzed on $4 \%$ polyacrylamide gels under non-denaturing conditions. In some cases, the protein extracts were incubated for 5 min with antibodies $(0.2 \mu \mathrm{l})$ before the labeled DNA fragment was added.

\section{In vitro transcription}

In vitro transcription was performed at $30^{\circ} \mathrm{C}$ in $25-\mu$ l assays containing $44 \mathrm{~mm}$ Tris- $\mathrm{HCl}(\mathrm{pH} 8.0), 14 \mathrm{~mm}$ DTT, $14 \mathrm{~mm}$ $\mathrm{MgCl}_{2}, 50 \mathrm{~mm} \mathrm{NaCl}, 4 \mathrm{~mm}$ EDTA, $300 \mu \mathrm{M}$ each of GTP, ATP, CTP, and $5 \mu \mathrm{M}$ of UTP, including $20 \mu \mathrm{Ci}$ of $\left[\alpha{ }^{32} \mathrm{P}\right] \mathrm{UTP}, 200 \mathrm{ng}$ of DNA, and $8 \mu$ l of enzyme extract if not otherwise indicated. Reactions were stopped after $30 \mathrm{~min}$ by extraction with phenolchloroform and precipitation with ethanol. Transcription products were analyzed on $8 \%$ acrylamide/urea gels.

\section{DNase I protection}

\section{pTZ19-16S-Ta pla
of DNA fragments}

To obtain the plasmid pTZ19-16S-Ta, the 163-bp EcoRI-HinPI fragment harboring the 16S rDNA promoter (Baeza et al. 1991) was cloned into the EcoRI-AccI sites of pUC 19. The fragment was isolated by EcoRI-PstI cleavage, recloned into Bluescript $\mathrm{KS}$, and resorted by HindIII-PstI cleavage. The resulting fragment was inserted into the multicloning site of pTZ19-Ta (Chen and Orozco 1988). Site-directed oligonucleotide mutagenesis was performed on this construction according to the protocol of Stratagene. For gel mobility-shift assays the inserts were cleaved with HindIII-BamHI. After purification on a $2 \%$ agarose gel the fragments were labeled by filling in with Klenow enzyme using $\left[\alpha^{-32}\right.$ P]dATP and $\left[\alpha^{-32}\right.$ P]dTTP.
The 274-bp EcoRI fragment harboring the 16S rDNA promoter (Baeza et al. 1991) was filled in with Klenow enzyme using $\left[{ }^{32} \mathrm{P}\right] \mathrm{dATP}$. After labeling, the fragment was cleaved by HhaI and the 163-bp promoter-containing fragment was isolated. DNA corresponding to $200,000 \mathrm{cpm}$ was incubated with $14 \mu \mathrm{l}$ of fraction CL (12 $\mu \mathrm{g}$ of protein) in the absence of $\mathrm{Mg}^{2+}$ under the same conditions as for gel retardation. For DNase I digestion the buffer was adjusted to $25 \mathrm{~mm} \mathrm{CaCl}_{2}, 10 \mathrm{mM} \mathrm{HEPES} \mathrm{(pH} \mathrm{7.6),} \mathrm{and}$ $22 \mathrm{~mm} \mathrm{MgCl} 2$. DNase I treatment was done for $30 \mathrm{sec}$ at $30^{\circ} \mathrm{C}$ using 2 units of DNase I. The reaction was stopped by adjustment of the solution to $20 \mathrm{~mm}$ EDTA, $250 \mathrm{~mm} \mathrm{NaCl}$, and $0.5 \%$ SDS, addition of $1 \mu \mathrm{g}$ of tRNA, and ethanol precipitation. The control reaction was incubated for the same time in the pres- 
ence of $12 \mu \mathrm{g}$ of BSA. The accompanying sequence was established by chemical cleavage of phosphodiester bonds $3^{\prime}$ of A and G (Negri et al. 1991).

\section{Oligonucleotides}

Labeled oligonucleotide hybrids were prepared as described previously (Baeza et al. 1991). For competition cross-linking experiments $2 \mu \mathrm{g}$ of oligonucleotides 1 and 2 or 3 and 4 was hybridized in $30 \mu$ l of $40 \mathrm{~mm}$ PIPES (pH 6.4), $1 \mathrm{~mm}$ EDTA, $0.4 \mathrm{~mm} \mathrm{NaCl}$, and $80 \%$ formanide overnight at $42^{\circ} \mathrm{C}$. Hybrids were precipitated, dissolved, and used as competitors without further purification: oligonucleotide 1, 5'-GAGAATGAATAAGAGGCTCGTGGGATT; oligonucleotide 2, TTACTTATTCTCCGAGCACCCTAACTC5'; oligonucleotide 3, 5'-GATACAAGTTATGCCTTGGAATGAA; oligonucleotide 4, TGTTCAATACGGAACCTTACTTTCT -5 '. In transcription and gel mobility-shift experiments a tetramer of the CDF2-binding site was used. To construct this tetramer the following two oligonucleotides were hybridized, ligated, and cloned into the SmaI site of pUC 18 after blunt-end formation by Klenow treatment: 5'-GGGAAAGAATGAATAAGAGGCTCGTGGGATTGACGTGAGG and TCTTACTTATTCTCCGAGCACCCTAACTGCACTCCCCCTT-5'. The tetramer was obtained by cleavage with EcoRI-PstI and electroelution after separation on $2 \%$ agarose gels.

\section{Acknowledgment}

We thank Dr. E.M. Orozco for kindly providing the transcription plasmids pTZ19-P $\mathrm{LS}^{-\mathrm{T} a}$ and $\mathrm{pTZ19-Ta}$, and M. Rocipon for photographic work.

The publication costs of this article were defrayed in part by payment of page charges. This article must therefore be hereby marked "advertisement" in accordance with 18 USC section 1734 solely to indicate this fact.

\section{References}

Baeza, L., A. Bertrand, R. Mache, and S. Lerbs-Mache. 1991. Characterization of a protein binding sequence in the promoter region of the 16S rRNA gene of the spinach chloroplast genome. Nucleic Acids Res. 19: 3577-3581.

Baumgartner, B.J., J.C. Rapp, and J.E. Mullet. 1993. Plastid genes encoding the transcription/translation apparatus are differentially transcribed early in Barley (Hordeum vulgare) chloroplast development. Plant Physiol. 101: 781-791.

Bradley, D. and A.A. Gatenby. 1985. Mutational analysis of the maize chloroplast ATPase- $\beta$ subunit gene promoter: The isolation of promoter mutants in $E$. coli and their characterization in a chloroplast in vitro transcription system. $E M B O$ I. 4: 3641-3648.

Briat, J.-F., C. Bisanz-Seyer, and A.-M. Lescure. 1987. In vitro transcription initiation of the rDNA operon of spinach chloroplast by a highly purified soluble homologous RNA polymerase. Curr. Genet. 11: 259-263.

Bülow, S. and G. Link. 1988. Sigma-like activity from mustard (Sinapis alba L.) chloroplasts conferring DNA-binding and transcription specificity to $E$. coli core RNA polymerase. Plant Mol. Biol. 10: 349-357.

Chen, L.-I. and E. Orozco. 1988. Recognition of procaryotic transcription terminators by spinach chloroplast RNA polymerase. Nucleic Acids Res. 16: 8411-8431.

Delp, G., G.L. Igloi, C.F. Beck, and H. Kössel. 1987. Functional in vivo verification in $E$. coli of promoter activities from the $\mathrm{rDNA} / \mathrm{tDNA}^{\mathrm{Val}}$ (GAC) leader region of Zea mays chloro- plasts. Curr. Genet. 12: 241-246.

Dormann-Przybyl, D., G. Strittmatter, and H. Kössel. 1986. The region distal to the rRNA operon from chloroplasts of maize contains genes coding for tRNA Arg (ACG) and the tRNA $^{\text {Asn }}$ (GUU). Plant Mol. Biol. 7: 419-431.

Eisermann, A., K. Tiller, and G. Link. 1990. In vitro transcription and DNA binding characteristics of chloroplast and etioplast extracts from mustard (Sinapis alba) indicate differential usage of the psbA promoter. EMBO 1. 9: 3981-3987.

Falk, J., A. Schmidt, and K. Krupinska. 1993. Characterization of plastid DNA transcription in ribosome deficient plastids of heat-bleached barley leaves. J. Plant Physiol. 141: 176-181.

Greenberg, B.M., J.O. Narita, C. DeLuca-Flaherty, W. Gruissem, K.A. Rushlow, and R.B. Hallick. 1984. Evidence for two RNA polymerase activities in Euglena gracilis chloroplasts. I. Biol. Chem. 259: 14880-14887.

Gruissem, W. and G. Zurawski. 1985a. Identification and mutational analysis of the promoter for a spinach chloroplast transfer RNA gene. EMBO J. 4: 1637-1644.

. 1985b. Analysis of promoter regions for the spinach chloroplast $r b c \mathrm{~L}, a t p \mathrm{~B}$ and $p s b \mathrm{~A}$ genes. EMBO $J$. 4: 33753383.

Gruissem, W., C. Elsner-Menzel, S. Latshaw, J.O. Narita, M.A. Schaffer, and G. Zurawski. 1986. A subpopulation of spinach chloroplast tRNA genes does not require upstream promoter elements for transcription. Nucleic Acids Res. 14: 75417555.

Hess, W.R., A. Prombona, B. Fieder, A.R. Subramanian, and T. Börner. 1993. Chloroplast $r p s 15$ and the $r p o B / C 1 / C 2$ gene cluster are strongly transcribed in ribosome-deficient plastids: Evidence for a functioning non-chloroplast-encoded RNA polymerase. EMBO I. 12: 563-571.

Hinkle, D.C. and M.J. Chamberlin. 1972. Studies of the binding of Escherichia coli RNA polymerase to DNA. I. Mol. Biol. 70: $157-185$.

Hu, J. and L. Bogorad. 1990. Maize chloroplast RNA polymerase: The 180-, 120-, and 38-kilodalton polypeptides are encoded in chloroplast genes. Proc. Natl. Acad. Sci. 87: 15311535.

Hu, J., R.F. Troxler, and L. Bogorad. 1991. Maize chloroplast RNA polymerase: The 78-kilodalton polypeptide is encoded by the plastid rpoC1 gene. Nucleic Acids Res. 19: 34313434.

Klein, U., J.D. De Camp, and L. Bogorad. 1992. Two types of chloroplast gene promoters in Chlamydomonas reinhardtii. Proc. Natl. Acad. Sci. 89: 3453-3457.

Lerbs, S., E. Bräutigam, and B. Parthier. 1985. Polypeptides of DNA-dependent RNA polymerase of spinach chloroplasts: Characterization by antibody-linked polymerase assay and determination of sites of synthesis. EMBO \%. 7: 1661-1666.

Lerbs, S., E. Bräutigam, and R. Mache. 1988. DNA-dependent RNA polymerase of spinach chloroplasts: Characterization of $\alpha$-like and $\sigma$-like polypeptides. Mol. \& Gen. Genet. 211: 459-464.

Lerbs-Mache, S. 1993. The 110-kDa polypeptide of spinach plastid DNA-dependent RNA polymerase: Single-subunit enzyme or catalytic core of multimeric enzyme complexes? Proc. Natl. Acad. Sci. 90: 5509-5513.

Lescure, A.-M., C. Bisanz-Seyer, H. Pesey, and R. Mache. 1985. In vitro transcription initiation of the spinach chloroplast 16S rRNA gene at two tandem promoters. Nucleic Acids Res. 13: 8787-8796.

Lewicki, B.T.U., T. Margus, J. Remme, and K.H. Nierhaus. 1993. Coupling of rRNA transcription and ribosomal assembly in vivo. I. Mol. Biol. 231: 581-593.

Link, G. 1984. DNA sequence requirements for accurate tran- 
scription of a protein-coding plastid gene in a plastid in vitro system from mustard (Sinapis alba L.). EMBO J. 3: 16971704.

Little, M.C. and R.B. Hallick. 1988. Chloroplast $r p o A, r p o B$, and rpoC genes specify at least three components of a chloroplast DNA-dependent RNA polymerase active in tRNA and mRNA transcription. $/$. Biol. Chem. 263: 14302-14307.

McGarvey, P., R.B. Helling, J.-Y. Lee, D.R. Engelke, and M.R. El-Gewely. 1988. Initiation of $r m$ transcription in chloroplasts of Euglena gracilis bacillaris. Curr. Genet. 14: 493500.

Mullet, J.E. 1993. Dynamic regulation of chloroplast transcription. Plant Physiol. 103: 309-313.

Morden, C.W., K.H. Wolfe, C.W. de Pamphilis, and J.D. Palmer. 1991. Plastid translation and transcription genes in a nonphotosynthetic plant: Intact, missing and pseudo genes. EMBO \%. 10: 3281-3288.

Narita, J.O., K.E. Rushlow, and R.B. Hallick. 1985. Characterization of an Euglena gracilis chloroplast RNA polymerase specific for ribosomal RNA genes. I. Biol. Chem. 260: 11194-11199.

Negri, R., G. Costanzo, and E. Di Mauro. 1991. A single-reaction method for DNA sequence determination. Anal. Biochem. 197: 389-395.

Orozco, E.M. Jr., J.E. Mullet, and N.-H. Chua. 1985. An in vitro system for accurate transcription initiation of chloroplast protein genes. Nucleic Acids Res. 13: 1283-1302.

Rajasekhar, V.K., E. Sun, R. Meeker, B.-W. Wu, and K.K. Tewari. 1991. Highly purified pea chloroplast RNA polymerase transcribes both rRNA and mRNA genes. Eur. $I$. Biochem. 195: 215-228.

Sexton, T.B., D.A. Christopher, and J.E. Mullet. 1990. Lightinduced switch in barley $p s b \mathrm{D}-p s b \mathrm{C}$ promoter utilization: A novel mechanism regulating chloroplast gene expression. EMBO I. 9: 4485-4494.

Sun, E., B.-W. Wu, and K.K. Tewari. 1989. In vitro analysis of the pea chloroplast 16S rRNA gene promoter. Mol. Cell. Biol. 9: 5650-5659.

Straney, D.C. and D.M. Crothers. 1985. Intermediates in transcription initiation from the E. coli lac UV5 promoter. Cell 43: 449-459.

Strittmatter, G., and H. Kössel. 1984. Cotranscription and processing of $23 \mathrm{~S}, 4.5 \mathrm{~S}$ and $5 \mathrm{~S}$ rRNA in chloroplasts from $\mathrm{Zea}$ mays. Nucleic Acids Res. 12: 7633-7647.

Strittmatter, G., A. Gozdzicka-Jozefiak, and H. Kössel. 1985. Identification of an rRNA operon promoter from Zea mays chloroplasts which excludes the proximal tRNA ${ }^{\text {val }}$ from the primary transcript. EMBO I. 4: 599-604.

Tiller, K., A. Eisermann, and G. Link. 1991. The chloroplast transcription apparatus from mustard (Sinapis alba L.). Eur. J. Biochem. 198: 93-99.

Tohdoh, N., K. Shinozaki, and M. Sugiura. 1981. Sequence of a putative region for the rRNA genes of tobacco chloroplast DNA. Nucleic Acids Res. 9: 5399-5406.

Zaitlin, D., J. Hu, and L. Bogorad. 1989. Binding and transcription of relaxed DNA templates by fractions of maize chloroplast extracts. Proc. Natl. Acad. Sci. 86: 876-880. 


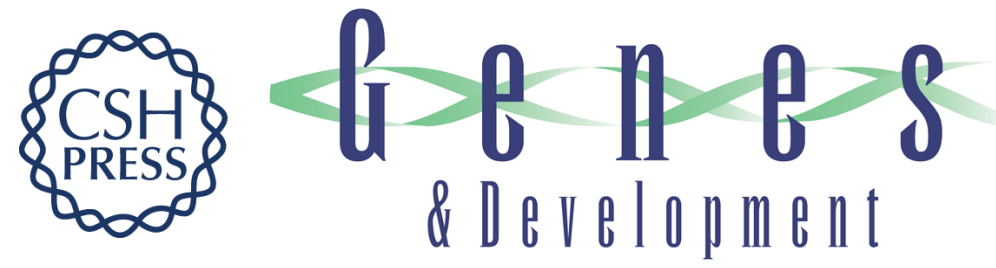

\section{Regulation of rDNA transcription in chloroplasts: promoter exclusion by constitutive repression.}

R Iratni, L Baeza, A Andreeva, et al.

Genes Dev. 1994, 8:

Access the most recent version at doi:10.1101/gad.8.23.2928

References This article cites 41 articles, 9 of which can be accessed free at:

http://genesdev.cshlp.org/content/8/23/2928.full.html\#ref-list-1

License

Email Alerting

Service

Receive free email alerts when new articles cite this article - sign up in the box at the top right corner of the article or click here.

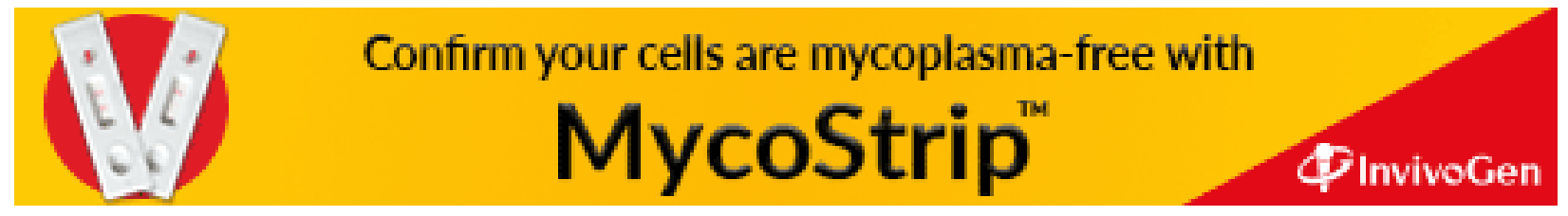

